\title{
A ética a partir de seus problemas e argumentos
}

\section{Problems and arguments on ethics}

\section{La ética a partir de sus problemas y argumentos}

\section{Alexandre Dittrich ${ }^{1}$}

[1] Universidade Federal do Paraná (UFPR), Brasil | Título abreviado: Ética. | Endereço para correspondência: Praça Santos Andrade, 50, $2^{\circ}$ andar. CEP: 80060-000. Curitiba, PR. | E-mail: aledittrich@ufpr.br

Resenha da obra: Textos Básicos de Ética: De Platão a Foucault, organizado por Danilo Marcondes (2009). Rio de Janeiro: Jorge Zahar. (Trabalho original publicado em 2007.).

O estudo de problemas éticos constitui uma das grandes subáreas da filosofia e produziu, ao longo da história dessa disciplina, uma quantidade intimidante de trabalhos. Naturalmente, o mesmo poderia ser dito, por exemplo, da epistemologia - e, nesse sentido, o mesmo problema se aplica a ambas: por onde começar? Como familiarizar-se com os principais problemas éticos e com as soluções propostas a eles ao longo da história da filosofia?

O leitor brasileiro conta agora com uma excelente opção: trata-se de Textos Básicos de Ética: De Platão a Foucault, de Danilo Marcondes, professor titular do Departamento de Filosofia da PUC-RJ e professor adjunto do Departamento de Filosofia da UFF. Marcondes já havia se notabilizado por publicar outras excelentes obras de cunho introdutório, como Iniciação à História da Filosofia (já em sua décima terceira edição) (1997/2010) e Textos Básicos de Filosofia (já em sua sétima edição) (1999/2011). Textos Básicos de Ética está agora em sua quarta edição.

O livro segue a mesma estrutura anteriormente adotada em Textos Básicos de Filosofia. Cada parte da obra é dedicada a um autor relevante na história da ética, em ordem cronológica: Platão, Aristóteles, Santo Agostinho, São Tomás de Aquino, Descartes, Spinoza, Hume, Kant, Kierkegaard, Nietzsche, Stuart Mill, Weber, Freud e Foucault. As partes começam com uma pequena introdução ao autor e às suas concepções sobre ética. Em seguida, são apresentados excertos de uma ou mais obras do autor que ilustram o cerne dessas concepções. Cada excerto é também precedido por uma breve introdução, indicando a natureza e a relevância das teses ali apresentadas. Por fim, cada parte apresenta um conjunto de questões visando a estimular a 
discussão dos textos precedentes, assim como algumas sugestões de leitura para aprofundamento - estas remetendo a obras sobre os autores, e não dos próprios.

Trabalhos dessa natureza podem, como admite o próprio Marcondes (2007/2009) em sua apresentação, suscitar ressalvas quanto à escolha de textos e autores. ${ }^{1}$ Ainda assim, não resta dúvida quanto à importância dos excertos que efetivamente constam do livro. Os analistas do comportamento encontrarão inúmeras oportunidades, ao longo da obra, de refletir sobre os problemas apresentados a partir de sua própria perspectiva. Além disso, notarão que muitos dos temas abordados pela análise do comportamento a partir, sobretudo, da obra de Skinner já constam há muito da pauta dos filósofos: ${ }^{2}$ a origem e a variedade dos costumes das diferentes culturas, a oposição entre determinismo e livre arbítrio, a importância das consequências de nosso comportamento (de curto ou longo prazo, para nós ou para outras pessoas) no julgamento ético, a tensão entre "impulsividade" e autocontrole, a pertinência e a eficácia da punição para suprimir o comportamento indesejável, a influência relativa de fatores naturais, individuais e culturais sobre o comportamento humano e as possibilidades e limites no ensino do comportamento ético - todos esses temas acabam por emergir nos textos apresentados.

$\mathrm{O}$ autocontrole como virtude ética, por exemplo, surge já no Górgias, de Platão (380 AC/1989). O mito do anel de Giges, exposto n'A República, do mesmo autor (380 AC/2003), é uma apresentação

1 A ausência de G. E. Moore e seu Principia Ethica (1903/2004), a despeito de qualquer julgamento que se faça sobre as teses que a obra apresenta, é digna de nota. É importante notar, além disso, que Marcondes (2007/2009) opta por não repetir excertos já publicados em Textos Básicos de Filosofia (1999/2011), o que acaba por excluir do livro partes d'A República de Platão (380 AC/2003) (a famosa Alegoria da Caverna), da Ética a Nicômaco de Aristóteles (350 AC/1985), das Confissões de Santo Agostinho (398 DC/1999), do Discurso do Método de Descartes (1637/1999) e da Fundamentação da Metafísica dos Costumes de Kant (1785/2007). Marcondes faz apenas uma descrição introdutória sobre a natureza e a relevância desses trechos (como faz com todos os demais), mas o leitor interessado em lê-los necessariamente precisa adquirir Textos Básicos de Filosofia.

2 Por si só, isso obviamente não confere ao que disseram nenhum privilégio especial. seminal de uma questão ética básica: os homens só agem de forma eticamente aceitável porque temem a punição? (O dito anel, como se sabe, permitia a Giges tornar-se invisível.) A obra de Aristóteles apresenta curiosas intuições iniciais (ainda que fortemente teleológicas) sobre a origem do sentimento de felicidade nas relações entre nossas ações e seus resultados. Marcondes (2007/2008) faz notar, além disso, a oposição entre Platão e Aristóteles no que diz respeito à possibilidade de ensinar as virtudes Platão afirmando-as inatas, Aristóteles afirmando-as resultantes do "hábito".

A filosofia cristã de Santo Agostinho e de São Tomás de Aquino ocupa-se com frequência do problema do livre arbítrio - embora seja possível a um analista do comportamento discordar de São Tomás quando diz que "o homem possui livre arbítrio, caso contrário seriam vãos os conselhos, as exortações, as ordens, as proibições, as recompensas e as punições" (Marcondes, 2007/2008, p. 62). No Tratado da Natureza Humana, de Hume (1739/2009), encontramos a famosa afirmação de que seria ilegítimo derivar proposições contendo ought (deve) de proposições contendo is (é) - isto é, valores de fatos, prescrições de descrições. Essa observação, que segundo Hume poderia "talvez ser considerada de alguma importância”, (Marcondes, $2007 / 2008$, p. 84) provou-se crucialmente influente para todas as reflexões éticas posteriores.

Com sua tradicional verve iconoclástica e irônica, Nietzsche zomba do projeto de uma ciência prescritiva da moral, afirmando que valores não são universais e apontando para as variações de costumes entre diferentes eras e culturas: "O que os filósofos denominavam 'fundamentação da moral', exigindo-a de si, era apenas, vista à luz adequada, uma forma erudita da ingênua fé na moral dominante" (Marcondes, 2007/2009, p. 106). A filosofia utilitarista, por sua vez, traz para o centro da discussão ética a avaliação das consequências de nossos atos, tentando estabelecê-las como critério de julgamento sobre seu valor. Especificamente no caso de Stuart Mill, trata-se de promover a felicidade (entendida como prazer) e evitar a infelicidade (entendida como dor). Observa Stuart Mill, porém, que os prazeres são considerados "tanto em relação à quantidade como à qualidade" (Marcondes, 2007/2009, p. 118) e que devemos 
buscar colocar "o interesse de cada indivíduo tanto quanto possível em harmonia com o interesse da totalidade ... de tal modo que seria para ele inconcebível a possibilidade de obter felicidade para si próprio com uma conduta oposta ao bem comum" (Marcondes, 2007/2009, p. 119). Como observa Marcondes (2007/2009) sobre a obra de Stuart Mill, porém, "não fica suficientemente claro como se dá a passagem do prazer, ou da realização, individual para o bem comum, o que tem suscitado um grande debate em torno das ideias utilitaristas até nossos dias" (p. 116).

Os três últimos autores contemplados na obra de Marcondes (2007/2009) ilustram como a ética (como, de resto, a filosofia) deixou progressivamente de ser província exclusiva de filósofos a partir do século 19: temos um sociólogo (Weber), um psicanalista (Freud) e um historiador (Foucault) - muito embora cada um deles possa, a seu modo, ser chamado filósofo. Weber radicaliza a análise das consequências de curto e longo prazo de nossas ações, revelando sua complexidade. Freud, por sua vez, descreve vividamente os atos do drama mental interno que explicariam a origem do sentimento de culpa - e, não surpreendentemente, acaba por dar pistas das variáveis externas que dariam margem à própria encenação do drama. ${ }^{3}$ Por fim, como que fechando um círculo, Foucault aplica seu método genealógico à história da sexualidade, destacando novamente o papel do autocontrole na antiguidade greco-romana - as "práticas de si", como ele as chama.

Surpreendentemente, todo esse rico conteúdo é apresentado em pouco mais de cento e quarenta páginas - o que acentua o caráter introdutório da obra. Ela pretende-se, é claro, um convite ao aprofundamento posterior. Nos limites do que se propõe, porém, dificilmente seria possível esperar algo melhor. É uma leitura fácil, agradável e, ainda assim, plena de recompensas - uma excelente introdução aos principais problemas e argumentos desenvolvidos no âmbito da ética.

3 A "severidade do superego", por exemplo, é "simplesmente ... uma continuação da severidade da autoridade externa" (Marcondes, 2007/ 2009, p. 130).
Naturalmente, há que se esperar, ao longo da trajetória proposta por Marcondes (2007/2009), uma generosa dose de explicações mentalistas - e a transformação do teatro da vida em um teatro mental interno (evidente, por exemplo, nos excertos d'As Paixões da Alma de Descartes (1649/1999), ou na tentativa de Kant de explicar a "menoridade" de boa parte dos seres humanos através de sua preguiça e covardia, ou em Freud, como vimos) mostra-se, mais uma vez, pouco útil para qualquer um que eventualmente queira fazer algo a respeito do comportamento das pessoas - incluindo aquilo que valorizam, ou o que sentem a respeito disso. A presença de explicações dessa natureza não deveria, é claro, surpreender os analistas do comportamento e não impede Textos Básicos de Ética de constituir-se em leitura altamente recomendável para esta comunidade.

\section{Referências}

Aristóteles (1985). Ética a Nicômaco (M. G. Kury, Trad.). Brasília: Editora da UnB. (Trabalho original publicado em $350 \mathrm{AC}$ )

Descartes, R. (1999). As paixões da alma (E. Corvisieri, Trad.). Em R. Descartes, Discurso do método / As paixões da alma / Meditações (Os pensadores) (pp. 101-232). São Paulo: Nova Cultural. (Trabalho original publicado em 1649)

Descartes, R. (1999). Discurso do método (E. Corvisieri, Trad.). Em R. Descartes, Discurso do método / As paixões da alma / Meditações (Os pensadores) (pp. 33-100). São Paulo: Nova Cultural. (Trabalho original publicado em 1637)

Hume, D. (2009). Tratado da natureza humana: Uma tentativa de introduzir o método experimental de raciocínio nos assuntos morais (D. Danowski, Trad.) (2 ed.). São Paulo: Editora UNESP. (Trabalho original publicado em 1739) Kant, I. (2007). Fundamentação da metafísica dos costumes (P. Quintela, Trad.). Lisboa: Edições 70. (Trabalho original publicado em 1785)

Marcondes, D. (2011). Textos básicos de filosofia: Dos pré-socráticos a Wittgenstein ( $7^{\mathrm{a}} \mathrm{ed}$.). Rio de Janeiro: Jorge Zahar. (Trabalho original publicado em 1999) 
Marcondes, D. (2010). Iniciação à história da filosofia (13 a ed.). Rio de Janeiro: Jorge Zahar. (Trabalho original publicado em 1997)

Marcondes, D. (2009). Textos básicos de ética: De Platão a Foucault (4 ${ }^{\mathrm{a}}$ ed.). Rio de Janeiro: Jorge Zahar. (Trabalho original publicado em 2007)

Moore, G. E. (2004). Principia ethica. Mineola: Dover. (Trabalho original publicado em 1903)

Platão (2003). A república (P. Nasseti, Trad.). São Paulo: Martin Claret. (Trabalho original publicado em torno de $380 \mathrm{AC}$ )

Platão (1989). Górgias (J. Bruna, Trad.). Rio de Janeiro: Bertrand Brasil. (Trabalho original publicado em torno de $380 \mathrm{AC}$ )

Santo Agostinho (1999). Confissões (J. O. Santos e A. A. Pina, Trad.) (Os pensadores). São Paulo: Nova Cultural. (Trabalho original publicado em 398 DC)

Informações do Artigo

Histórico do artigo:

Submetido em: 14/11/2012

Primeira decisão editorial: 16/01/2013

Aceito em: 25/02/2013 